\title{
Chemical characterization of lipopolysaccharides from Legionella feeleii, Legionella hackeliae and Legionella jordanis
}

\author{
Anders Sonesson, ${ }^{1}+$ Erik Jantzen, ${ }^{1}$ Torill Tangen ${ }^{1}$ and Ulrich Zähringer ${ }^{2}$
}

Author for correspondence: Anders Sonesson. Tel: +4646336000 . Fax: +4646336666.

\footnotetext{
1 National Institute of Public Health, Geitmyrsveien 75, $\mathrm{N}-0462$ Oslo, Norway

2 Forschungsinstitut Borstel, Parkallee 22, D-23845

Borstel, Germany
}

\begin{abstract}
Lipopolysaccharides (LPS) from Legionella feeleii serogroup 1, L. hackeliae serogroup 1 and $L$. jordanis were subjected to chemical analysis. All three LPS contained D-mannose, D-glucose, D-glucosamine, L-glycero-D-manno-heptose, 2-keto-3-deoxyoctonic acid and glycerol. In addition the LPS of $L$. feeleii was characterized by L-quinovose (tentatively identified) and L-fucosamine, $L$. hackeliae LPS by D-quinovosamine, D-galactosamine and D-galacturonic acid, and $L$. jordanis LPS by D-quinovosamine. Phosphorylated sugars were detected in all three LPS. The backbone sugar of the lipid A part was in each case 2,3diamino-2,3-dideoxy-D-glucose substituted with a complex pattern of fatty acid, including 20-22 different amide-linked (non-branched and methylbranched) 3-hydroxy fatty acids of chain-length ranging from 12 to 23 carbon atoms. The fatty acid patterns included also ester-linked nonhydroxylated entities and the uncommon 27-oxo-octacosanoic acid and 29-oxotriacontanoic acid. The LPS of $L$. hackeliae and $L$. jordanis also contained heptacosane-1,27dioic and nonacosane-1,29-dioic acid, and their 2-hydroxy analogues were characteristic of $L$. jordanis LPS. SDS-PAGE patterns of the three LPS were distinctly different. Both $L$. feeleii and $L$. jordanis produced smooth-form $L P S$ with characteristic ladder patterns, whereas $L$. hackeliae LPS were of more rough-type character.
\end{abstract}

Keywords: Legionella, lipid A, taxonomy, long-chain fatty acids

\section{INTRODUCTION}

Lipopolysaccharides (LPS) of species from genus Legionella appear to share a unique complex fatty acid pattern. Of the four Legionella LPS described all contain between 16 and 22 amide-linked 3-hydroxy fatty acids and several long-chain ( $\omega$-1)-oxo fatty acids (Sonesson $e t$ al., 1989b, 1994; Moll et al., 1992). This unique LPS composition correlates well with the distinct wellseparated phylogenetic position $(\gamma-2)$ of genus Legionella among Gram-negative taxa, as revealed by $16 \mathrm{~S}$ rRNA sequence analysis (Woese et al., 1985; Fry et al., 1991).

As part of a chemotaxonomic study of Legionella, com-

† Present address: Astra Draco AB, Bioanalytical Chemistry, PO Box 34, S-22100 Lund, Sweden.

Abbreviations: ASA, amino acid analyser; GICN3N, 2,3-diamino-2,3dideoxy-D-glucose; HPAEC, high-pH anion-exchange chromatography; HVPE, high-voltage paper electrophoresis; Kdo, 2-keto-3-deoxyoctonic acid; PED, pulsed electrochemical detector; PCP, phenol/chloroform/petroleum ether solvent; PS, polysaccharide; TFA, trifluoroacetyl; TMS, trimethylsilyl- parative analyses of LPS isolated from $L$. feeleii, $L$. backeliae and L. jordanis were performed. These three LPS share high complexity in their fatty acid pattern but with distinct differences of practical potential for diagnostic application.

\section{METHODS}

Bacterial strains. L. feeleii serogroup 1 (ATCC 35072), L. backeliae serogroup 1 (ATCC 35250) and L. jordanis (ATCC $33623)$ were grown $\left(2 \mathrm{~d}, 37^{\circ} \mathrm{C}\right)$ on buffered charcoal yeast extract (BCYE agar, Oxoid) and harvested as described previousily (Sonesson et al., 1989b). The cells of Yersinia enterocolitica Ye 128 and $\mathrm{O}: 6,31$ were grown and harvested as described by Jantzen \& Lassen (1980).

Isolation of LPS. LPS was extracted from lyophilized bacterial cells using a combination of the hot phenol-water method (Westphal et al., 1952) as modified by Johnson \& Perry (1976), the phenol/chloroform/petroleum ether (PCP) method of Galanos et al. (1979) and finally by repeated washings with diethyl ether followed by chloroform/methanol $(2: 1, \mathrm{v} / \mathrm{v})$ as described (Sonesson et al., 1994).

The LPS was cleaved into lipid A and polysaccharide (PS) with 
(a)

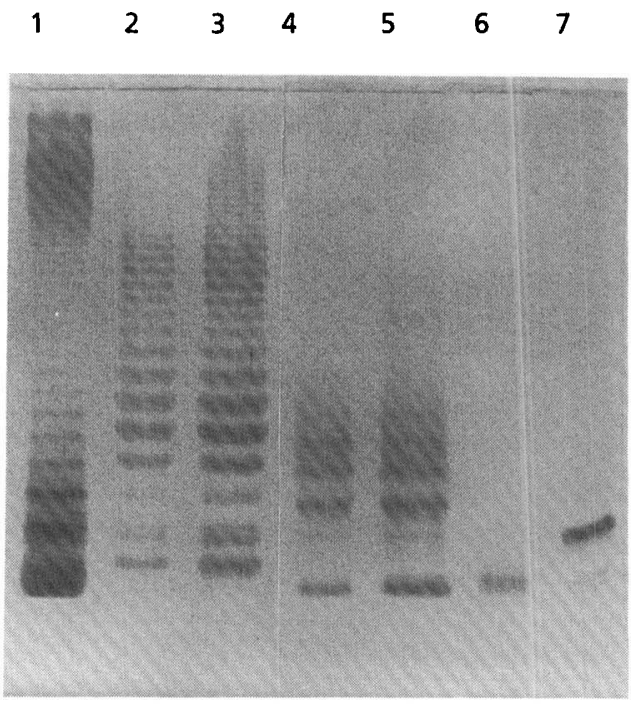

(b)

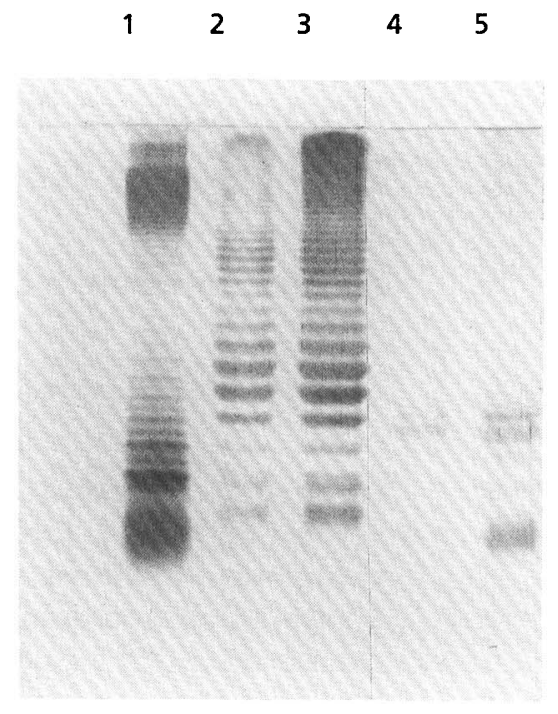

Fig. 1. (a) Silver-stained glycine SDS-PAGE of LPS from S. abortusequi S-type (lane 1, $0.8 \mu \mathrm{g}$ ), L. feeleii (lanes $2,2 \mu \mathrm{g}$, and 3, $5 \mu \mathrm{g}$ ), L. jordanis (lanes 4, $3 \mu \mathrm{g}$, and 5, $6 \mu \mathrm{g}$ ), S. minnesota Ra-type (lane 6, $1 \mu \mathrm{g}$ ), S. helsinkii SR-type (lane 7, $1 \mu \mathrm{g}$ ) applied to the $16.5 \%$ acrylamide gel. (b) $S$. abortusequi S-type (lane 1, 0.8 $\mu \mathrm{g}$ ), L. feeleii (lanes $2,2 \mu \mathrm{g}$, and $3,5 \mu \mathrm{g}$ ) and $\mathrm{L}$. hackeliae (lanes $4,1 \mu \mathrm{g}$, and $5,4 \mu \mathrm{g}$ ) applied to a $18 \%$ acrylamide gel.

$1 \%$ acetic acid at $100^{\circ} \mathrm{C}$ for $2 \mathrm{~h}$ (Wilkinson et al., 1973), and the lipid A part was isolated as a pellet after centrifugation $(1000 \mathrm{~g})$. The PS part was recovered from the supernatant as described (Sonesson et al., 1994).

A smooth (S)-type reference LPS of Salmonella abortusequi was a gift from Dr O. Lüderitz, Max-Planck-Institut für Immunbiologie, Freiburg, Germany, and $S$. belsinkii SR LPS as well as $S$. minnesota Ra LPS, were supplied by Dr I. Helander, National Public Health Institute, Helsinki, Finland.

Analytical methods. The analytical methods and instrumental conditions applied in this study have been described in detail recently (Moll et al., 1992; Sonesson \& Jantzen, 1992; Sonesson et al., 1989b, 1994).

Neutral and amino sugars were quantified both as alditol acetate derivatives and as trifluoroacetyl (TFA) methyl glycosides by $\mathrm{GC}$, and as free sugars by high- $\mathrm{pH}$ anion-exchange chromatography (HPAEC) with pulsed electrochemical detection (PED). Amino sugars were also analysed by high-voltage paper electrophoresis (HVPE), TLC and amino acid analyser (ASA). Total hexosamine content was determined by the MorganElson reaction as modified by Strominger et al. (1959). 2-Keto3-deoxyoctonic acid (Kdo) was quantified after methanolysis $\left(2 \mathrm{M} \mathrm{HCl}\right.$ in methanol, $60^{\circ} \mathrm{C}, 2 \mathrm{~h}$ ) and TFA derivatization by GC (Bryn \& Jantzen, 1986), and also colorimetrically by the thiobarbituric acid reaction (Waravdekar \& Saslaw, 1959) after hydrolysis with $0.1 \mathrm{M}$ sodium acetate buffer $\mathrm{pH} 4.4\left(100^{\circ} \mathrm{C}, 1 \mathrm{~h}\right)$ (Brade et al., 1983). Uronic acids were determined by HPAECPED, GC and by the modified carbazole method (Bitter \& Muir, 1962) and their identification was also supported by GCMS of their 6,6-dideuterio-substituted alditol acetate derivatives (Dudman et al., 1983). Phosphorylated sugars were determined indirectly by recording the increase of GC peak area after dephosphorylation of samples with aqueous $48 \%(\mathrm{w} / \mathrm{w})$ hydrofluoric acid at $4{ }^{\circ} \mathrm{C}$ for $72 \mathrm{~h}$ (Sonesson et al., 1989a). Phosphorylated sugars were also detected by HPAEC-PED, ASA and by GC analysis of trimethylsilyl (TMS) derivatized methyl glycosides (Zamze et al., 1987). Absolute configurations of the sugars were determined by GC analysis of 2-(R)-butyl and 2-(S)-butyl glycoside diastereomeric derivatives (Gerwig et al., 1978) after TFA derivatization and retention time comparison to authentic standards.

Fatty acids were determined as methyl esters by GC. Hydroxyl groups were acetylated, TFA- or TMS-derivatized prior to GC analyses.

Analyses by GC were performed using fused-silica columns and flame-ionization detection. Besides retention time comparison, the identification of sugars and fatty acids was verified by GCMS.

PAGE. SDS-PAGE was carried out as described by Laemmli (1970) using a $4 \%(\mathrm{w} / \mathrm{v})$ stacking gel and a $16 \%$ or $18 \%$ separating gel. Gels were either silver stained for LPS (Tsai \& Frasch, 1982), or with Coomassie brilliant blue for detection of proteins (Reisner et al., 1975).

Miscellaneous estimations. Phosphate was determined by the method of Lowry et al. (1954); nucleic acids were determined by ultraviolet absorption at $260 \mathrm{~nm}$. RNA contamination was also indicated by GC analyses of ribose. Protein was measured by the Lowry method using serum albumin as standard. Presence of ornithine-containing lipids was examined by GC analysis of ornithine (Sonesson et al., 1988).

\section{RESULTS}

\section{General properties of the LPS}

LPS of $L$. feeleii and L. hackeliae were recovered from the waterphase after the hot phenol-water extraction whereas L. jordanis LPS was isolated from the phenolic phase. All three LPS preparations were further purified by the PCP extraction method. Addition of water to the phenolic PCP extracts failed to induce precipitation of LPS. Instead, LPS of L. feeleii and L. backeliae precipitated upon addition of ethanol, and addition of diethyl ether (Moll et al., 1992) 
Table 1. Constituents of the polysaccharide part of Legionella LPS

LPS results are expressed as nmol per mg LPS dry weight. For comparison the PS values are given relative to the LPS values by setting the D-mannose values equal. Corresponding absolute values (nmol per $\mathrm{mg}$ dry wight of PS) can be obtained by using a factor of 2.38 for L. feeleii; 2.48 for L. backeliae; and 2.03 for L. jordanis.

\begin{tabular}{|c|c|c|c|c|c|c|}
\hline \multirow[t]{2}{*}{ Component } & \multicolumn{2}{|c|}{ L. feeleii } & \multicolumn{2}{|c|}{ L. hackeliae } & \multicolumn{2}{|c|}{ L. jordanis } \\
\hline & PS & LPS & PS & LPS & PS & LPS \\
\hline Glycerol & ND & 8 & 14 & 14 & 19 & 50 \\
\hline Glycerol phosphate & 5 & 7 & ND & ND & 37 & 49 \\
\hline L-Rhamnose & ND & ND & 1 & 3 & 14 & 18 \\
\hline L-Quinovose* & 215 & 231 & ND & ND & ND & ND \\
\hline D-Mannose & 369 & 369 & 99 & 99 & 107 & 107 \\
\hline D-Glucose & 18 & 14 & 4 & 2 & 36 & 45 \\
\hline D-Glucose phosphate & ND & ND & 63 & 57 & 31 & 34 \\
\hline D-Glycero-D-manno-heptose & 28 & 25 & ND & ND & 14 & 13 \\
\hline L-Glycero-D-manno-heptose & 44 & 49 & 2 & 1 & 33 & 31 \\
\hline L-Glycero-D-manno-heptose phosphate & ND & ND & 4 & 4 & ND & ND \\
\hline Kdo & 35 & 42 & 78 & 91 & 38 & 46 \\
\hline Galacturonic acid $\dagger$ & ND & ND & 131 & 125 & ND & ND \\
\hline D-Glucosamine & 165 & 196 & 208 & 241 & 123 & 157 \\
\hline D-Glucosamine-phosphate & 386 & 352 & ND & ND & 168 & 179 \\
\hline D-Galactosamine & ND & ND & 219 & 235 & ND & ND \\
\hline D-Galactosamine-phosphate & ND & ND & 205 & 219 & ND & ND \\
\hline D-Quinovosamine $\ddagger$ & ND & ND & 930 & 1042 & 1442 & 1614 \\
\hline L-Fucosamine $\ddagger$ & 559 & 593 & ND & ND & ND & ND \\
\hline GlcN3N & ND & 246 & ND & 210 & ND & 197 \\
\hline Total hexosamine & $\mathrm{NP}$ & 422 & $\mathrm{NP}$ & 1191 & $\mathrm{NP}$ & 1250 \\
\hline Kdo colorimetric $\|$ & $\mathrm{NP}$ & 56 & NP & 58 & NP & 41 \\
\hline Total phosphate & 423 & 514 & 314 & 636 & 196 & 432 \\
\hline
\end{tabular}

ND, Not detected; NP, not performed.

* Tentatively identified.

† Measured by the modified carbazole method.

$\ddagger$ Quantified as alditol acetate derivative by GC using the same response factor as for glucosamine.

$\int$ Total hexosamine content obtained by the Morgan-Elson reaction.

$\|$ Measured by the thiobarbituric reaction test after hydrolysis in $0.1 \mathrm{M}$ acetate $(\mathrm{pH} 4.4)$ at $100{ }^{\circ} \mathrm{C}$ for $60 \mathrm{~min}$.

induced precipitation of $L$. jordanis LPS. The final LPS preparations of $L$. feeleii and $L$. backeliae were soluble in water. In contrast, $L$. jordanis LPS was insoluble in water but completely soluble in chloroform/methanol $(2: 1$, $\mathrm{v} / \mathrm{v}$ ). The yields of LPS ( $\%$ bacterial dry weight) were $0.7 \%$ for L. feeleii, $1.8 \%$ for $L$. hackeliae and $2.1 \%$ for $L$. jordanis, respectively.

The preparation of L. jordanis LPS was essentially free from nucleic acids $(<0.1 \%$ by weight) and protein $(<$ $0.1 \%$ by weight). Corresponding values for $L$. feeleii LPS were $2 \%$ and $3 \%$ and for L. backeliae LPS $3 \%$ and $2 \%$, respectively. Ornithine (marker for ornithine-containing lipids) and palmitoleic acid (phospholipid marker) were undetectable by GC in all three LPS preparations.

Cleavage of LPS yielded $22 \%$ of lipid A and $51 \%$ of PS for L. feeleii (of LPS dry weight); corresponding values for L. hackeliae were $15 \%$ and $63 \%$, and for L. jordanis $27 \%$ and $47 \%$, respectively.

The SDS-PAGE profiles of the three LPS preparations were distinctly different (Fig. 1). L. feeleii LPS showed a characteristic S-type form LPS profile with distinct ladderlike bands covering both low and high molecular mass regions (Fig. 1). L. jordanis LPS also exhibited a ladder pattern but the spaces between the bands were somewhat larger and the range smaller (Fig. 1a). L. hackeliae LPS gave a more rough $(\mathrm{R})$-form type profile with a major band in the low molecular mass region (Fig. 1b).

\section{Chemical composition of the three LPS}

The chemical compositions of the LPS isolates are presented in Tables 1 and 2 . The analyses accounted for $69 \%$ of L. feeleii LPS, $73 \%$ of L. backeliae LPS and $76 \%$ 
Table 2. Constituents of the lipid A part of Legionella LPS

LPS results are expressed as nmol per mg LPS dry weight. For comparison the lipid A values are given relative to the LPS values by setting the 3-OH-i14:0 values equal for L. feeleii; the 3-OH-n20:0 values equal for $L$. hackeliae: and the 3-OH-a 15:0 values equal for $L$. jordanis. Corresponding absolute values (nmol per mg dry weight of lipid A) can be obtained by using a factor of $2 \cdot 24$ for L. feeleii; $2 \cdot 14$ for L. backeliae; and 2.30 for L. jordanis.

\begin{tabular}{|c|c|c|c|c|c|c|}
\hline \multirow[t]{2}{*}{ Component } & \multicolumn{2}{|c|}{ L. feeleii } & \multicolumn{2}{|c|}{ L. hackeliae } & \multicolumn{2}{|c|}{ L. jordanis } \\
\hline & $\begin{array}{c}\text { Lipid } \\
\text { A }\end{array}$ & LPS & $\begin{array}{c}\text { Lipid } \\
\text { A }\end{array}$ & LPS & $\begin{array}{c}\text { Lipid } \\
\text { A }\end{array}$ & LPS \\
\hline Glycerol & 8 & 8 & 12 & 14 & 4 & 50 \\
\hline Glycerol-phosphate & ND & 7 & 9 & 14 & ND & 49 \\
\hline D-Glucosamine & 24 & 196 & 21 & 241 & 38 & 157 \\
\hline Glc3N3 & 236 & 246 & 229 & 210 & 207 & 197 \\
\hline Total phosphate & 104 & 431 & 220 & 636 & 155 & 432 \\
\hline \multicolumn{7}{|l|}{ Amide-linked FA* } \\
\hline 3-OH-n12:0 & 3.9 & $4 \cdot 1$ & $2 \cdot 7$ & $3 \cdot 0$ & $2 \cdot 1$ & $2 \cdot 3$ \\
\hline 3-OH-n13:0 & $3 \cdot 7$ & $3 \cdot 5$ & $3 \cdot 8$ & $4 \cdot 1$ & $4 \cdot 6$ & $4 \cdot 9$ \\
\hline 3-OH-i14:0 & 73 & 73 & 72 & 75 & 57 & 59 \\
\hline 3-OH-n14:0 & 54 & 50 & 33 & 36 & 21 & 19 \\
\hline 3-OH-a15:0 & 31 & 29 & 74 & 76 & 103 & 103 \\
\hline 3-OH-n15:0 & $2 \cdot 3$ & $2 \cdot 2$ & $1 \cdot 9$ & $2 \cdot 0$ & $2 \cdot 4$ & $2 \cdot 5$ \\
\hline $3-\mathrm{OH}-\mathrm{i} 16: 0$ & ND & ND & $3 \cdot 1$ & $3 \cdot 0$ & $4 \cdot 5$ & $4 \cdot 3$ \\
\hline 3-OH-n16:0 & $5 \cdot 9$ & $5 \cdot 8$ & 5.9 & $6 \cdot 1$ & $7 \cdot 7$ & $7 \cdot 6$ \\
\hline 3-OH-a17:0 & $4 \cdot 0$ & $3 \cdot 8$ & $3 \cdot 1$ & $2 \cdot 9$ & $1 \cdot 8$ & 1.9 \\
\hline 3-OH-n17:0 & 0.8 & $0 \cdot 7$ & $2 \cdot 9$ & $2 \cdot 7$ & 1.9 & $1 \cdot 7$ \\
\hline 3-OH-i18:0 & ND & ND & $2 \cdot 2$ & $2 \cdot 0$ & $7 \cdot 6$ & $7 \cdot 4$ \\
\hline 3-OH-n18:0 & 39 & 42 & 12 & 10 & 19 & 20 \\
\hline 3-OH-a19:0 & $1 \cdot 8$ & $1 \cdot 9$ & $1 \cdot 6$ & $1 \cdot 5$ & 30 & 29 \\
\hline 3-OH-n19:0 & $5 \cdot 1$ & $5 \cdot 4$ & $4 \cdot 1$ & $3 \cdot 8$ & $7 \cdot 3$ & $7 \cdot 2$ \\
\hline 3-OH-i20:0 & $6 \cdot 2$ & $5 \cdot 9$ & 0.5 & 0.5 & $5 \cdot 6$ & $5 \cdot 4$ \\
\hline 3-OH-n20:0 & 69 & 71 & 87 & 87 & 48 & 45 \\
\hline $3-\mathrm{OH}-\mathrm{i} 21: 0$ & $1 \cdot 8$ & $2 \cdot 0$ & $3 \cdot 4$ & $3 \cdot 1$ & ND & ND \\
\hline 3-OH-a21:0 & $4 \cdot 7$ & $5 \cdot 1$ & 12 & 10 & 31 & 29 \\
\hline $3-\mathrm{OH}-\mathrm{n} 21: 0$ & 22 & 20 & $9 \cdot 1$ & $8 \cdot 8$ & $6 \cdot 3$ & $5 \cdot 9$ \\
\hline $3-\mathrm{OH}-\mathrm{i} 22: 0$ & $2 \cdot 3$ & $2 \cdot 4$ & $2 \cdot 3$ & $2 \cdot 1$ & $5 \cdot 2$ & $5 \cdot 1$ \\
\hline $3-\mathrm{OH}-\mathrm{n} 22: 0$ & 48 & 45 & 39 & 37 & $2 \cdot 8$ & $2 \cdot 6$ \\
\hline 3-OH-a23:0 & $2 \cdot 6$ & $2 \cdot 7$ & $3 \cdot 0$ & $2 \cdot 8$ & ND & ND \\
\hline Sum amide-linked FA & 381 & 376 & 379 & 379 & 369 & 363 \\
\hline \multicolumn{7}{|c|}{ Ester-linked FA normal chain length } \\
\hline i14:0 & $2 \cdot 2$ & $2 \cdot 8$ & ND & ND & $0 \cdot 9$ & $1 \cdot 3$ \\
\hline a15:0 & $5 \cdot 6$ & $5 \cdot 8$ & 13 & 17 & 34 & 39 \\
\hline $\mathrm{n} 15: 0$ & $3 \cdot 3$ & 3.4 & $1 \cdot 8$ & $2 \cdot 0$ & ND & ND \\
\hline i16:0 & 26 & 30 & 22 & 27 & 18 & 21 \\
\hline $\mathrm{n} 16: 0$ & 55 & 61 & 32 & 37 & $1 \cdot 2$ & $1 \cdot 4$ \\
\hline a17:0 & 15 & 17 & 23 & 27 & 19 & 23 \\
\hline $\mathrm{n} 17: 0$ & ND & ND & $1 \cdot 0$ & 0.9 & ND & ND \\
\hline $\mathrm{n} 18: 0$ & $3 \cdot 1$ & 3.5 & $1 \cdot 8$ & $1 \cdot 9$ & $1 \cdot 0$ & $1 \cdot 1$ \\
\hline $\mathrm{n} 20: 0$ & $5 \cdot 8$ & 6.0 & $1 \cdot 5$ & $1 \cdot 8$ & $1 \cdot 1$ & $1 \cdot 2$ \\
\hline Sum & 116 & 130 & 96 & 115 & 75 & 88 \\
\hline \multicolumn{7}{|l|}{ Long chain length $\nmid$} \\
\hline $27-\mathrm{OH}-\mathrm{n} 28: 0$ & 14 & 14 & trace & trace & $3 \cdot 7$ & $5 \cdot 1$ \\
\hline 27-oxo-n28:0 & 214 & 238 & 113 & 122 & 145 & 164 \\
\hline 29-oxo-n30:0 & 31 & 37 & 55 & 58 & 46 & 50 \\
\hline n27:0-dioic & ND & ND & 17 & 15 & $7 \cdot 8$ & 10 \\
\hline
\end{tabular}


Table 2 (cont.)

\begin{tabular}{|c|c|c|c|c|c|c|}
\hline \multirow[t]{2}{*}{ Component } & \multicolumn{2}{|c|}{ L. feeleii } & \multicolumn{2}{|c|}{ L. hackeliae } & \multicolumn{2}{|c|}{ L. jordanis } \\
\hline & $\begin{array}{c}\text { Lipid } \\
\mathbf{A}\end{array}$ & LPS & $\begin{array}{c}\text { Lipid } \\
\mathbf{A}\end{array}$ & LPS & $\begin{array}{c}\text { Lipid } \\
\mathbf{A}\end{array}$ & LPS \\
\hline n29:0-dioic & ND & ND & 108 & 112 & $8 \cdot 3$ & 11 \\
\hline 2-OH-27-oxo-n28:0 & ND & ND & ND & ND & 50 & 57 \\
\hline 2-OH-29-oxo-n30:0 & ND & ND & ND & ND & 13 & 16 \\
\hline 2-OH-n27:0-dioic & ND & ND & ND & ND & 18 & 20 \\
\hline 2-OH-n29:0-dioic & ND & ND & ND & ND & 19 & 22 \\
\hline Sum & 259 & 289 & 293 & 309 & 311 & 355 \\
\hline Sum ester-linked FA & 375 & 419 & 389 & 422 & 386 & 443 \\
\hline Ratio amide/ester linked FA & $1 \cdot 0$ & $0 \cdot 9$ & $1 \cdot 0$ & 0.9 & $1 \cdot 0$ & 0.8 \\
\hline
\end{tabular}

ND, Not detected.

* Fatty acids are designated by the number of total carbon atoms with prefixes ' a' for anteiso-branching,

' $i$ ' for iso-branching, ' $n$ ' for normal chain and $\mathrm{OH}$ for hydroxyl substitution with the position indicated.

$\dagger$ Long-chain fatty acids were quantified using the response factor of the methyl ester derivative of n27:0, $\mathrm{n} 28: 0$ and $\mathrm{n} 30: 0$ relative to $\mathrm{n} 22: 0$ (internal standard).

of L. jordanis LPS, dry weight respectively. All three LPS preparations were rich in phosphate and contained phosphorylated sugars (see below). Ethanolamine pyrophosphate was detected by ASA (not quantified) in LPS of L. hackeliae and L. jordanis.

Neutral sugars. All three LPS contained D-mannose, Dglucose and L-glycero-D-manno-heptose and glycerol (Table 1). The heptose isomer D-glycero-D-manno-heptose was also identified in LPS of $L$. feeleii and $L$. jordanis, and minor amounts of L-rhamnose was found in LPS of L. backeliae and L.. jordanis. Phosphorylated neutral sugars detected included glycerol phosphate in LPS of $L$. feeleii and $L$. jordanis, glucose phosphate in L. backeliae and L. jordanis, and L-glycero-D-manno-heptose phosphate in L. backeliae LPS. Due to phosphate migration during hydrolysis (both $\alpha$ - and $\beta$-glycerophosphate were detected) and the lack of standards, the phosphate position of the phosphorylated sugars could not be determined.

L. feeleii LPS contained significant amounts of an unusual compound (X). GC-MS analysis indicated a 6deoxyhexose structure but the retention time differed from that of commonly occurring 6-deoxyhexoses, Lrhamnose and L-fucose (Lindberg, 1990). LPS of $Y$. enterocolitica Ye 128, reported to contain 6-deoxy-L-altrose (Hoffman et al., 1980), and LPS of Y. enterocolitica serovar 6,31, reported to contain 6-deoxygulose (Kalmykova et al., 1988), were isolated. Three different derivatives were prepared from hydrolysates/methanolysates of these LPS preparations as well as for the commercial available 6deoxy-D-glucose: alditol acetates, acetyl and TFA methyl glycosides. The retention times of the different 6deoxyhexose derivatives were compared to that of compound $\mathrm{X}$. The derivatives of 6 -deoxyaltrose eluted clearly ahead of those from $X$, whereas derivatives of 6deoxyglucose and 6-deoxygulose had approximately the same retention as X. By co-injection with preparations of L. feeleii LPS (using both nonpolar and polar columns) the derivatives of 6-deoxyglucose (quinovose) were shown to possess retention characteristics identical to those for X, whereas the derivatives of 6-deoxygulose did not fully coincide. Other 6-deoxyhexose configurations (i.e. allo, ido and talo) all have GC retention properties clearly distinct from the gluco configuration (Voiland \& Michel, 1985) and were therefore not investigated. The TFA 2-(R)-butyl glycoside diastereomer derivative of $\mathrm{D}$ quinovose and the TFA 2-(S)-butyl glycoside diastereomer derivative of $\mathrm{X}$ showed identical retention times, whereas corresponding derivatives of 2-(S)-butyl D-quinovosides and 2-(R)-butyl glycosides of $\mathrm{X}$ had divergent retention times. These results tentatively indicated L-quinovose as a major neutral sugar constituent of $L$. feeleii LPS. NMR studies are needed to confirm the gluco configuration.

Amino sugars. D-Glucosamine was present in all three LPS. Glucosamine phosphate was detected in LPS of L. feeleii and L. jordanis and in 66 and $50 \mathrm{~mol} \%$ of total glucosamine content, respectively. D-Galactosamine was only present in L. backeliae LPS and about $50 \mathrm{~mol} \%$ was phosphorylated (Table 1).

All three LPS contained a 2-amino-2,6-dideoxyhexose as a major constituent. L. feeleii LPS contained $\mathrm{L}$-fucosamine, identified by ASA, HPAEC-PED and GC whereas LPS of $L$. backeliae and $L$. jordanis contained the isomer $\mathrm{D}$ quinovosamine.

The presence of 2,3-diamino-2,3-dideoxy-D-glucose (GlcN3N) in all three LPS was verified by HVPE and ninhydrin staining. Identical retention and characteristic orange-brown staining (Mayer et al., 1990) to the GlcN3N standard were obtained. Corresponding results were 
obtained by TLC. Retention time and mass spectra obtained by GC-MS were identical to that of the GlcN3N standard, the electron impact (EI) mass spectrum in accordance with that reported by Roppel et al. (1975).

The total hexosamine values obtained by the MorganElson reaction were lower than the total molar amounts of unphosphorylated hexosamine and 2-amino-2,6dideoxyhexosamine obtained by GC.

Acidic sugars. Kdo was identified as the TFA methyl glycoside derivative by GC-MS in all three LPS investigated. Molar amounts of Kdo obtained by the thiobarbituric acid reaction were in approximately the same range (Table 1) and no increased amounts of Kdo were obtained when analysing dephosphorylated LPS. Attempts to detect a 2-keto-octonic acid-Kdo disaccharide, as found in LPS of $L$. israelensis and L. micdadei (Sonesson et al., 1994), were negative. Galacturonic acid was detected in L. hackeliae LPS by HPAEC-PED and GC-MS, and was quantified by the modified carbazole method. No uronic acids were detected in LPS of $L$. feeleii and L. jordanis, either by chromatographic techniques or by the colorimetric assay performed.

\section{Fatty acid composition}

The fatty acids identified included fatty acids with methylbranched (anteiso and iso) and linear carbon chains (Table 2). Both LPS of L. feeleii and L. backeliae contained eight nonhydroxy fatty acids with palmitic acid as the major one, whereas L. jordanis LPS contained seven and with 12 methyltetradecanoic acid as the most abundant.

Twenty different 3-hydroxy fatty acids were identified in LPS of L. feeleii and L. jordanis; two more were detected in $L$. backeliae LPS, in the range $C_{12}$ to $C_{23}$. The major 3-hydroxy acid in L. feeleii LPS was 3-hydroxy. 12-methyltridecanoic acid, in $L$. hackeliae LPS 3hydroxycosanoic acid and in L. jordanis LPS 3-hydroxy. 12-methyltetradecanoic acid.

The long-chain oxo acids 27-oxo-octacosanoic acid and 29-oxotriacontanoic acid occurred in all three LPS. Dioic long-chain acids (i.e. heptacosane-1,27-dioic and nonacosane-1,29-dioic acid) were identified in LPS of $L$. backeliae and L. jordanis. In addition, L. jordanis LPS contained the 2-hydroxy analogues of these four acids. Their identification has been published separately (Moll et al., 1992; Sonesson et al., 1993). LPS of L. feeleit and $L$. jordanis were also found to contain 27 hydroxyoctacosanoic acid. 27-Oxo-octacosanoic acid was the most prominent fatty acid in all three LPS (Table 2).

The 3-hydroxy fatty acids were all found to be bound in stable (presumably amide) linkages whereas the nonhydroxy acids and the long-chain hydroxy, oxo and dioic acids were all ester-linked. The molar distribution of the fatty acid classes in LPS of L. feeleii were $17 \%$ nonhydroxy acids, $47 \%$ 3-hydroxy fatty acids and $36 \%$ long-chain acids. Corresponding molar fatty acid values in LPS of L. backeliae were $14 \%, 47 \%$ and $39 \%$, and in LPS of L. jordanis $11 \%, 45 \%$ and $44 \%$, respectively.

\section{Composition of lipid A preparations}

Three sugars were identified in the lipid A preparations, mainly GlcN3N and minor amounts of glucosamine and glycerol (Table 2). The molar proportion between GlcN3N and glucosamine was approximately 10:1 in lipid A of L. feeleii and L. backeliae, and 5:1 in lipid A of L. jordanis. Hydrofluoric acid treatment did not increase the amounts of GlcN3N and glucosamine, only glycerol in lipid A of L. hackeliae increased. Molar amounts of phosphate in the lipid A preparations were moderate.

The fatty acid profiles of native LPS were grossly recovered in the lipid A preparations. The analyses accounted for $69 \%, 68 \%$ and $72 \%$ of the lipid isolates (dry weight) of L. feeleii, L. backeliae and L. jordanis LPS, respectively.

\section{Composition of the polysaccharide parts}

With the exception of GlcN3N, the sugars determined in the native LPS preparations were also found in the PS part preparations (Table 1). The molar proportions suggested that minor losses of neutral sugars and some degradation of Kdo occurred during cleavage of LPS. The phosphorylated sugars identified in the LPS preparations were components of the PS chains and the PS isolates were found to be rich in phosphate. No fatty acids were detected in the PS preparations.

The analyses accounted for (of PS dry weight) $85 \%$ of the L. feeleii PS, $91 \%$ of the L. backeliae PS and $78 \%$ of the $L$. jordanis PS, respectively.

\section{DISCUSSION}

L. feeleii serogroup $1, L$. backeliae serogroup 1 and $L$. jordanis belong to the more frequently occurring human pathogenic species of Legionella. All three have been isolated from patients who contracted Legionnaires' disease or pontiac fever (Fang et al., 1989). Only L. feeleii can be identified relatively easily, being oxidase and $\beta$ lactamase negative, and unable to liquefy gelatin (Brenner, 1987). The distinguishing phenotypic features of $L$. backeliae and L. jordanis, on the other hand, are sparse. Also fatty acid profiles (Mayberry, 1992; Jantzen et al., 1993) and ubiquinone patterns of profiles of L. hackeliae and $L$. jordanis are quite related and typical of several Legionella species. Those of $L$. feeleii are more specific, and especially its ubiquinone pattern appears to be a useful diagnostic feature (Lambert \& Moss, 1989; Wilkinson $e t$ al., 1990).

As found for other LPS of Legionella species (Moll et al., 1992; Sonesson et al., 1989b, 1994), the LPS of this study were characterized by a remarkably complex pattern of fatty acids including long-chain ( $\omega$-1)-oxo fatty acids (Table 2). The long-chain dioic acids found in $L$. hackeliae and $L$. jordanis appear not to be as general LPS constituents of Legionella as 27-oxo-octacosanoic acid, which so far has been found in LPS of 15 Legionella species (unpublished results). The 2-hydroxy27-oxo-octacosanoic acid, 2-hydroxy-29-oxotriacontanoic acid, 2-hydroxyheptacosane-1,27-dioic acid and 2- 
hydroxynonacosane-1,29-dioic acid found in $L$. jordanis LPS were also detected in LPS of $L$. maceachernii and $L$. micdadei (Sonesson et al., 1994), whereas the 27hydroxyoctacosanoic acid constituent of $L$. feeleii and $L$. jordanis LPS was originally identified in LPS of Rhizobium trifolii (Hollingsworth \& Lill-Elghanian, 1989). 27Hydroxyoctacosanoic acid and other $(\omega-1)$-hydroxy fatty acids are described as chemotaxonomic hallmarks of species belonging to the $\alpha-2$ branch of Proteobacteria (Bhat et al., 1991), but appear thus also to be characteristic of several Legionella species, of the $\gamma-2$ branch of Proteobacteria.

The main lipid A backbone sugar was found to be GlcN3N for all three LPS. This sugar has so far only been encountered in nature as a lipid A backbone sugar and is a hallmark of Nitrobacter and Rbodopseudomonas as the sole lipid A sugar. Lipid A backbones consisting of GlcN3N and additional small amounts of glucosamine are characteristic of other genera such as Chromatium and Bradyrbizobium (Mayer et al., 1990). The LPS of this study appear to belong to the latter group in this respect since minor, apparently nonstoichiometric, amounts of glucosamine were identified in the lipid A preparations. Low amounts of glycerol were also detected and its origin appears not to have been phospholipids since palmitoleic acid (phospholipid marker) was not detected in lipid A or LPS preparations.

The sugar compositions of the three LPS were quite different from one another. Generally, amino sugars dominated quantitatively, and the presence of a 2-amino2,6-dideoxyhexose as well as D-glucosamine, in $L$. backeliae also D-galactosamine, was noteworthy. Several rare LPS sugar constituents were identified. L-Quinovose, tentatively identified in $L$. feeleii LPS, has so far not been reported as a LPS constituent (Lindberg, 1990). Galactosamine phosphate, found in PS of $L$. backeliae LPS, is also uncommon. Glucose phosphate, present in LPS of L. backeliae and L. jordanis, has also been found in LPS of other Legionella species (Sonesson et al., 1989b, 1994), in Acinetobacter calcoaceticus LPS (Kawahara et al., 1987) and in Pseudomonas pavonacea (Wilkinson et al., 1973). Glycerol phosphate, recently reported in the O-chain of $Y$. kristensenii LPS (L'vov et al., 1992), was found in all three LPS of this study and has previously also been detected in other Legionella LPS (Sonesson et al., 1994). Galacturonic acid, a common component of bacterial extracellular PS and LPS (Lindberg, 1990), was identified in $L$. backeliae LPS and represents the first uronic acid detected in LPS of Legionella.

In studies of whole-cell sugar composition of $L$. jordanis an $O$-methyl pentose and an unusual hexose were reported (Fox et al., 1990); these components were not detected in the LPS preparation of L. jordanis.

In contrast to LPS of L. feeleii and L. backeliae, L. jordanis LPS partitioned exclusively into the phenolic phase during extraction and was only partially soluble in water but completely soluble in chloroform/methanol $(2: 1$, $\mathrm{v} / \mathrm{v})$. Similar hydrophobic character also characterizes LPS of L. pneumophila (Conlan \& Ashworth, 1986; unpublished results), but was nevertheless fairly surprising due to the S-type character of L. jordanis LPS revealed by SDS-PAGE (Fig. 1). At least six bands were evident, separated by relatively large spatial distances indicating a large repeating O-chain unit, probably with D-quinovosamine as the main constituent. L. feeleii LPS also showed a typical S-type ladder pattern with at least 24 bands, whereas L. hackeliae LPS revealed a more R-type character.

A relation between phylogenetic grouping based on $16 \mathrm{~S}$ rRNA sequence data and LPS composition has been demonstrated for bacteria of the $\alpha-2$ and $\alpha-3$ subdivisions of Proteobacteria (Bhat $e$ t al., 1991; Mayer et al., 1990). The results obtained so far indicate that also the $\gamma-2$ branch of Proteobacteria, which includes the species of Legionella, can be described by a unique LPS composition, with the complex fatty acid substitution of lipid $A$ as the most outstanding chemotaxonomic hallmark. However, both the fatty acid and the sugar patterns appear to contain several markers useful for species differentiation. Further chemical studies of Legionella LPS are in progress to extend this chemotaxonomic description of the genus.

\section{ACKNOWLEDGEMENTS}

The technical assistance of Sabine Barten for performing amino sugar analyses on an amino sugar analyser, and Hermann Moll for expert mass spectrometric analyses, are gratefully acknowledged. Dieter Grimmecke is gratefully acknowledged for valuable discussions in sugar chemistry. This work was supported by the Royal Norwegian Council for Scientific and Industrial Research, the Swedish Institute and Nordic Ministerial Council.

\section{REFERENCES}

Bhat, U. R., Carlson, R. W., Busch, M. \& Mayer, H. (1991). Distribution and phylogenetic significance of 27hydroxyoctacosanoic acid in lipopolysaccharides from bacteria belonging to the alpha-2 subgroup of Proteobacteria. Int J Syst Bacteriol 41, 213-217.

Bitter, T. \& Muir, H. M. (1962). A modified uronic acid carbazole reaction. Anal Biochem 4, 330-334.

Brade, H., Galanos, C. \& Lüderitz, O. (1983). Differential determination of the 3-deoxy-D-mannooctulosonic acid residues in lipopolysaccharides of Salmonella minnesota rough mutants. Fur $J$ Biochem 131, 195-200.

Brenner, D. J. (1987). Classification of the legionellae. Semin Respir Infect 2, 190-205.

Bryn, K. \& Jantzen, E. (1986). Quantification of 2-keto-3deoxyoctonate in (lipo)polysaccharides by methanolytic release, trifluoroacetylation and capillary gas chromatography. J Chromatogr 370, 103-112.

Conlan, J. W. \& Ashworth, L. A. E. (1986). The relationship between the serogroup antigen and lipopolysaccharide of Legionella pneumophila. J Hyg Camb 96, 39-48.

Dudman, W. F., Franze'n, L.-E., Darvill, J. E., McNeil, M., Darvill, A. G. \& Albersheim, P. (1983). The structure of the acidic polysaccharide secreted by Rhizobium phaseoli strain $127 \mathrm{~K} 36$. Carbobydr Res 117, 141-156.

Fang, G.-D., Yu, V. L. \& Vickers, R. M. (1989). Disease due to the Legionellaceae (other than Legionella pneumophila). Historical, 
microbiological, clinical, and epidemiological review. Medicine 68, 116-132.

Fox, A., Rogers, J. C., Fox, K. F., Schnitzer, G., Morgan, S. L., Brown, A. \& Aono, R. (1990). Chemotaxonomic differentiation of legionellae by detection and characterization of aminodideoxyhexoses and other unique sugars using gas chromatography-mass spectrometry. J Clin Microbiol 28, 546-552.

Fry, N. K., Warwick, S., Saunders, N. A. \& Embley, T. M. (1991). The use of $16 \mathrm{~S}$ ribosomal RNA analyses to investigate the phylogeny of the family Legionellaceae. J Gen Microbiol 137, $1215-1222$

Galanos, V., Lüderitz, O. \& Westphal, O. (1979). Preparation and properties of a standardized lipopolysaccharide from Salmonella abortus equi (Novo-Pyrexal). Zentralbl Bakteriol 243, 226-244.

Gerwig, G. J., Kamerling, J. P. \& Vliegenthart, J. F. G. (1978). Determination of the $\mathrm{D}$ and $\mathrm{L}$ configuration of neutral monosaccharides by high-resolution capillary G.L.C. Carbobydr Res 62, 349-357.

Hoffman, J., Lindberg, B. \& Brubaker, R. R. (1980). Structural studies of the O-specific side-chains of the lipopolysaccharide from Yersinia enterocolitica Ye 128. Carbobydr Res 78, 212-214.

Hollingsworth, R. I. \& Lill-Elghanian, D. A. (1989). Isolation and characterization of the unusual lipopolysaccharide component, 2-amino-2-deoxy-2- $\mathrm{N}$-(27-hydroxyoctacosanoyl)-3-O-(3hydroxytetradecanoyl)-gluco-hexuronic acid, and its de-O-acylation product from the free lipid A of Rbizobium trifolii ANU843. J Biol Chem 264, 14039-14042.

Jantzen, E. \& Lassen, J. (1980). Characterization of Yersinia species by analysis of whole-cell fatty acids. Int J Syst Bacteriol 30, 421-428.

Jantzen, E., Sonesson, A., Tangen, T. \& Eng, J. (1993). Hydroxyfatty acid profiles of Legionella species: diagnostic usefulness assessed by principal component analysis. J Clin Microbiol 31, 1413-1419.

Johnson, K. G. \& Perry, M. B. (1976). Improved techniques for the preparation of bacterial lipopolysaccharides. Can J Microbiol 22 29-34.

Kalmykova, E. N., Gorshkova, R. P., Isakov, V. V. \& Ovodov, Y. S. (1988). Structural studies of side-chains of the O-specific polysaccharide from lipopolysaccharide of Yersinia enterocolitica serovar O:6.31. Bioorg Kbim 14, 652-657.

Kawahara, K., Brade, H., Rietschel, E. T. \& Zähringer, U. (1987). Studies on the chemical structure of the core-lipid A region of the lipopolysaccharide of Acinetobacter calcoaceticus NCTC 10305. Detection of a new 2-octulosonic acid interlinking the core oligosaccharide and lipid A component. Eur J Biochem 163, 489-495.

Laemmli, U. K. (1970). Cleavage of structural proteins during the assembly of the head of bacteriophage T4. Nature 227, 680-685.

Lambert, M. A. \& Moss, C. W. (1989). Cellular fatty acid compositions and isoprenoid quinone contents of 23 Legionella species. J Clin Microbiol 27, 465-473.

Lindberg, B. (1990). Components of bacterial polysaccharides. In Advances in Carbobydrate Chemistry and Biochemistry Vol. 48, pp. 279-318. Edited by R. S. Tipson \& D. Horton. San Diego: Academic Press.

Lowry, O. H., Roberts, N. R., Leiner, K. Y., Wu, M.-L. \& Farr, A. L. (1954). The quantitative histochemistry of brain. I. Chemical methods. J Biol Chem 207, 1-17.

L'vov, V. L., Gur'yanova, S. V., Rodionov, A. V. \& Gorshkova, R. P. (1992). Structure of the repeating unit of the O-specific polysaccharide of the lipopolysaccharide of Yersinia kristensenii strain 490 (O:12,25). Carbobydr Res 228, 415-422.

Mayberry, W. R. (1992). Nonhydroxy, monohydroxy and di- hydroxy cellular fatty acid profiles of Legionella species: an update. Abstract. International symposium on Legionella, 26-29 January 1992, Orlando, FL, USA.

Mayer, H., Krauss, J. H., Yokota, A. \& Weckesser, J. (1990). Natural variants of lipid A. In Endotoxin, pp. 45-70. Edited by H. Friedman, T. W. Klein, M. Nakano \& A. Nowotny. New York: Plenum Publishing Corporation.

Moll, H., Sonesson, A., Jantzen, E., Marre, R. \& Zähringer, U. (1992). Identification of 27-oxo-octacosanoic acid and heptacosane1,27-dioic acid in Legionella pneumopbila. FEMS Microbiol Lett 97, $1-6$.

Reisner, A. H., Nemes, P. \& Bucholtz, C. (1975). The use of Coomassie brilliant blue G250 perchloric acid solution for staining in electrophoresis and isoelectric focusing on polyacrylamide gels. Anal Biochem 64, 509-516.

Roppel, J., Mayer, H. \& Weckesser, J. (1975). Identification of a 2,3diamino-2,3-dideoxyhexose in the lipid A component of lipopolysaccharides of Rhodopseudomonas viridis and Rhodopseudomonas palustris. Carbobydr Res 40, 31-40.

Sonesson, A. \& Jantzen, E. (1992). The branched-chain octose yersiniose $A$ is a lipopolysaccharide constituent of Legionella micdadei and Legionella maceachernii. J Microbiol Methods 15, 241-248.

Sonesson, A., Larsson, L., Fox, A., Westerdahl, G. \& Odham, G. (1988). Determination of environmental levels of peptidoglycan and lipopolysaccharide using gas chromatography with negativeion chemical-ionization mass spectrometry utilizing bacterial amino acids and hydroxy fatty acids as biomarkers. J Chromatogr 431, 1-15.

Sonesson, A., Bryn, K., Jantzen, E. \& Larsson, L. (1989a). Gas chromatographic determination of (phosphorylated) 2-keto-3deoxyoctonic acid, heptoses and glucosamine in bacterial lipopolysaccharides after treatment with hydrofluoric acid, methanolysis and trifluoroacetylation. J Chromatogr 487, 1-7.

Sonesson, A., Jantzen, E., Bryn, K., Larsson, L. \& Eng, J. (1989b). Chemical composition of a lipopolysaccharide from Legionella pneumophila. Arch Microbiol 153, 72-78.

Sonesson, A., Moll, H., Jantzen, E. \& Zähringer, U. (1993). Longchain $\alpha$-hydroxy-( $\omega$ - 1$)$-oxo fatty acids and $\alpha$-hydroxy-1, $\omega$-dioic fatty cells are cell wall constituents of Legionella ( $L$. jordanis, $L$. maceachernii and L. micdadei). FEMS Microbiol Lett 106, 315-320.

Sonesson, A., Jantzen, E., Bryn, K., Tangen. T., Eng, J. \& Zähringer, U. (1994). Composition of 2,3-dihydroxy fatty acid-containing lipopolysaccharides from Legionella israelensis, Legionella maceachernii and Legionella micdadei. Microbiology 140, 1261-1271.

Strominger, J. L., Park, J. T. \& Thompson, R. E. (1959). Composition of the cell wall of Staphylococcus aureus: its relation to the mechanism of action of penicillin. J Biol Chem 234, 3263-3268.

Tsai, C.-M. \& Frasch, C. E. (1982). A sensitive silver stain for detecting lipopolysaccharides in polyacrylamide gels. Anal Biochem 119, 115-119.

Voiland, A. \& Michel, G. (1985). Characterization of 6-deoxy-Daltritol in the cell-wall polysaccharide of Nocardia asteroides R 399. Carbohydr Res 141, 283-288.

Waravdekar, V. S. \& Saslaw, L. D. (1959). A sensitive colorimetric method for the estimation of 2-deoxy sugars with the use of the malonaldehyde-thiobarbituric acid reaction. J Biol Chem 234, 1945-1950.

Westphal, O., Lüderitz, O. \& Bister, F. (1952). Über die extraktion von bakterien mit phenol/wasser. Z Naturforsch 7b, 148-155.

Wilkinson, S. G., Galbraith, L. \& Lightfoot, G. A. (1973). Cell walls, lipids, and lipopolysaccharides of Pseudomonas species. Eur J Biochem 33, 158-174.

Wilkinson, I. J., Sangster, N., Ratcliff, R. M., Mugg, P. A., Davos, 
D. E. \& Lanser, J. A. (1990). Problems associated with identification of Legionella species from the environment and isolation of six possible new species. Appl Environ Microbiol 56, 796-802.

Woese, C. R., Weisburg, W. G., Hahn, C. M., Paster, B. J., Zablen, L. B., Lewis, B. J., Macke, T. J., Ludwig, W. \& Stackebrandt, E. (1985). The phylogeny of purple bacteria: the gamma subdivision. Syst Appl Microbiol 6, 25-33.
Zamze, S. E., Ferguson, M. A. J., Moxon, E. R., Dwek, R. A. \& Rademacher, T. W. (1987). Identification of phosphorylated 3deoxy-manno-octulosonic acid as a component of Haemopbilus influenzae lipopolysaccharide. Biochem J 245, 583-587.

Received 14 April 1994; revised 16 May 1994; accepted 25 May 1994. 